\title{
O feminino em dois romances de Lídia Jorge e Paulina Chiziane
}

\section{Débora Leite David ${ }^{1}$}

RESUMO: Na análise comparativa dos romances $A$ costa dos murmúrios, de Lídia Jorge, e Ventos do apocalipse, de Paulina Chiziane, interessa-nos as figuras femininas que participam de modo nuclear nas respectivas tramas. Em comum existem as mulheres consideradas coletivamente e aquelas anônimas, espécie de distorção imagética que as deslocam de suas referências identitárias, mas que é superada pelo diálogo ativo nas situações sociais que lhes servem de referência.

ABSTRACT: On comparative analysis of the novels A Costa dos Murmúrios, by Lídia Jorge and Ventos do Apocalipse, by Paulina Chiziane, we care about the feminine characters that participate into plots in a nuclear way. In common there are the women treated in a collective and anonymous way, a kind of imagery distortion that move their identity references, which is, nevertheless, defeated by an active dialogue on social situations.

PALAVRAS-CHAVE: Identidade; mito; desconstrução; feminino.

KEYWORDS: Identity; mith; desconstruction; feminine.

A leitura dos romances $A$ costa dos murmúrios e Ventos do apocalipse permite-nos observar como Lídia Jorge e Paulina Chiziane ${ }^{2}$ são capazes de projetar em suas narrativas uma perspectiva de desconstrução ${ }^{3}$ do universo beligerante masculino. Este olhar feminino que atravessa as lentes do universo feminino alcança o horror da guerra como espaço fundamentalmente de pertencimento dos homens. No entanto, ao invés do enaltecimento de feitos pretensamente heróicos durante a guerra, deparamo-nos com uma visão demolidora da imagem mitificada do herói, seja ele romantizado pelo idealismo e pela utopia, ou ainda na sua forma

${ }^{1}$ Doutoranda em Estudos Comparados de Literaturas de Língua Portuguesa, FFLCH-USP. Pesquisa: $O$ desencanto utópico ou o juízo final: Um estudo comparado entre "A costa dos murmúrios", de Lídia Jorge e "Ventos do apocalipse", de Paulina Chiziane. Email: dleitedavid@uol.com.br.

${ }^{2}$ Paulina Chiziane nasceu em 1955 ao sul de Moçambique. Estreou como escritora com o romance Balada de amor ao vento, em 1990. Seguiram os romances Ventos do apocalipse em 1995, O sétimo juramento em 2000, e Niketche, uma história de poligamia em 2002. Apesar da pequena produção literária até o momento, Paulina Chiziane é considerada pela crítica uma das revelações mais promissoras da literatura moçambicana, além de ser a primeira mulher moçambicana a publicar um romance. Recebeu, ex-aequo, o Prêmio José Craveirinha de Literatura em 2003 pelo romance Niketche, uma história de poligamia, ao lado de Mia Couto.

${ }^{3}$ Apesar de tratar-se de termo cunhado pelos críticos norte-americanos num processo de simplificação das idéias de Jacques Derrida, usaremos essa denominação, lembrando sempre que importa em leitura minuciosa de textos da tradição ocidental (filosóficos e literários), para desconstruir seus pressupostos idealistas, dualistas, logocêntricos e etnocêntricos, privilegiando a dúvida, o que difere sempre a síntese. Assim, os conceitos são colocados permanentemente sob reflexão e ajustes. 
clássica de guerreiro imbatível, representada pela força física e beligerância. ${ }^{4}$ Essa demolição da imagem mítica da guerra que se dá com o desvendamento destas duas figurações emblemáticas do universo masculino aponta para uma visão crítica diferenciada do cenário bélico presente nas referidas narrativas e suas conseqüências históricas e sociais.

Neste cenário de beligerância o espaço-território contemplado em ambos os romances é o mesmo país, Moçambique, ${ }^{5}$ mas em momentos singulares. Enquanto Lídia Jorge apresenta-nos um esboço dos bastidores cruéis da Guerra Colonial que se estendeu durante toda a década de 1960 e terminou somente com a Revolução dos Cravos em 25 de abril de 1974, Paulina Chiziane revela-nos aspectos da violência e desesperança causadas pela Guerra Civil $^{6}$ que se seguiu à Independência de Moçambique ocorrida em 25 de junho de 1975. Este poderia ser o principal de muitos pontos de contato entre os romances - o espaço-território, que, em verdade, apresenta-se como elemento de maior obviedade e que paira sobre a superfície das narrativas. No entanto, não toca ao espaço físico o lume crítico que se busca na presente reflexão, e sim ao espaço periférico e híbrido convulsionado pela guerra sobre o qual estão construídas as narrativas de Lídia Jorge ${ }^{7}$ e Paulina Chiziane. Periférico não apenas pela condição dos países a que se referem as narrativas Portugal como periferia da Europa e Moçambique como país "não-desenvolvido" e assim na periferia do mundo globalizado, como também o espaço periférico em que está contido o

\footnotetext{
${ }^{4} \mathrm{O}$ contraponto existente entre os universos masculino e feminino nos romances a serem analisados sustenta-se no equilíbrio que existe na complementaridade recíproca e na importância das suas diferenças que devem ser compreendidas, mas nunca rechaçadas. Não são apenas os homens que fazem a guerra como nos ensina Paulina Chiziane: "Em todas as guerras do mundo nunca houve arma mais fulminante que a mulher, mas é aos homens que cabem as honras de generais". Cf. CHIZIANE, 1999, p. 20.

${ }^{5}$ Vale destacar que no romance de Lídia Jorge, a ambientação construída na então colônia de Moçambique traduz-se em espaço de desvendamento da realidade portuguesa através da desconstrução de mitos históricos e ideológicos cultivados pela ditadura salazarista durante seus quase 40 anos de existência.

${ }^{6}$ A Guerra Civil Moçambicana se estendeu durante quase duas décadas após a Independência do país, e terminou somente em 1992 com a assinatura do Acordo de Roma (04/10/1992). Cf. VENTURA, 2006, p. 156.

${ }^{7}$ Lídia Jorge nasceu em 1946 ao sul de Portugal. Licenciada em Filologia Românica pela Universidade de Lisboa e professora do ensino secundário, a partir de 1970 viveu um período em Angola e Moçambique onde lecionava. Escritora de expressivo sucesso na literatura portuguesa possui extensa produção literária premiada. Iniciou a carreira com o romance, $O$ dia dos prodígios, concluído em 1978 e publicado em 1980, cuja narrativa encerra um Portugal ainda sob a ditadura salazarista. Ao mesclar níveis narrativos onde exibe personagens de dimensão mítica em seus dois primeiros romances ( $O$ dia dos prodígios e $O$ cais das merendas), Lídia Jorge foi associada à literatura sulamericana pela crítica, formando um "realismo mágico português" ao lado de João de Melo, Mário de Carvalho e Gabriela Llansol. Também escreveu os romances Notícia da cidade silvestre (1984, Prêmio Literário do Município de Lisboa), A costa dos murmúrios (1988), A última dona (1992), O jardim sem limites (1995, Prêmio Bordalo de Literatura da Casa da Imprensa), O vale da paixão (1998, Prêmio Bordalo de Literatura da Casa da Imprensa, Prêmio D. Diniz da Fundação Casa de Mateus, Prêmio P.E.N. Clube Português de Ficção e Prix Jean Monnet de Littérature Européenne) e $O$ vento assobiando nas gruas (2002, Grande Prêmio de Romance e Novela APE/IPLB, Prêmio Correntes d'Escritas).
} 
universo feminino. Híbrido em razão da pluralidade de identidades e culturas para além da dominação portuguesa, tendo em vista a existência de numerosas etnias no espaço-território delimitado pelas fronteiras nacionais moçambicanas.

Esse espaço, subjacente ao discurso ficcional de cada um dos romances, é compartilhado por diferentes identidades em tensão, que nos leva à cultura portuguesa e às culturas das várias etnias, como a maconde, a macua e a tsonga, entre outras, em movimentos de aproximação e oposição. Respeito à diferença e intolerância em relação a ela se disputam. A diferença afigura-se às vezes como mediadora das realidades e responsável pela possibilidade de novas perspectivas críticas, como bem assinala Paulina Chiziane no seguinte trecho de uma de suas entrevistas:

Estou a trabalhar em Quelimane e descobri que o meu país é grande e que eu penetrei na cultura do outro. Hoje vejo o mundo com outros olhos e ganhei esta diversidade cultural que ajuda um escritor a transpor as suas idéias para o papel. Estou num outro mundo no mesmo mundo. Tudo é diferente, desde a maneira como as mulheres vêem a vida, o mundo. Não é pior nem melhor, mas é diferente. ${ }^{8}$

Essa perspectiva crítica através da escrita, notadamente aquela filtrada nos textos literários produzidos por mulheres, importa no avanço pelo campo da escrita, território de domínio essencialmente dos homens. E mais do que tão somente produção literária, trata-se, outrossim, da consolidação da posição feminina em relação ao campo intelectual, o que implicará em olhares diferenciados e até então contidos na periferia da intelectualidade e da escrita literária. Por conseguinte, torna-se de extrema relevância a reflexão acerca da oralidade para as mulheres que chegaram tardiamente à escrita e à participação mais ativa na intelectualidade.

Face às especificidades críticas que possibilitam numerosos diálogos entre os referidos romances, vale notar, especialmente, a elaboração formal empreendida por Lídia Jorge e Paulina Chiziane, e que se traduz numa ficção muito burilada, delicadamente incutida de perspectivas críticas agudas sobre situações e fatos histórico-sociais extremamente relevantes à segunda metade do século XX. Entre a agonia do fim da dominação colonial e o desalento trágico da guerra civil, e através de olhares críticos oriundos de pólos plurais e dialéticos entre si, as

\footnotetext{
${ }^{8}$ Vale notar que a escritora moçambicana é oriunda da região sul de Moçambique (Gaza) e que colaborou intensamente no socorro às vítimas da guerra civil na região norte, sofrendo ela própria atentados em algumas oportunidades. Talvez, por isso, seja possível encontrar concomitantemente em seus romances peculiaridades culturais, ritos e tradições do norte e do sul de Moçambique. Cf. JAMISSE, 2003/2004, p. 138.
} 
referidas narrativas nos colocam frente a tópicos incontornáveis e sempre presentes como o questionamento quanto às identidades e a desconstrução e sobrevivência dos mitos.

\section{Os círculos infernais}

Apesar das situações diferenciadas em que se desenvolvem as narrativas das escritoras de Moçambique e de Portugal, especialmente no tocante a uma possível datação histórica dos acontecimentos antes e depois da Independência de Moçambique, há um diálogo entre dois espaços sociais bem marcados nos romances: a cidade e o campo, o urbano e o rural. O romance de Lídia Jorge mostra-nos o ambiente urbano da cidade da Beira, longe do conflito armado que ocorre mais ao norte de Moçambique, e está centrado no grupo de oficiais e suas famílias. Mais especificamente, suas mulheres confinadas no Hotel Stella Maris enquanto os homens lutam longe dali. O romance de Paulina Chiziane está voltado para o cenário rural, a aldeia de Mananga, ao norte de Moçambique, onde acontecem os conflitos armados, possivelmente da Guerra Civil. Após o massacre da aldeia, os sobreviventes partem em busca de local mais seguro, a aldeia do Monte. O caminho é feito em parte no meio da mata para escapar dos ataques aéreos e dos conflitos em terra. Homens, mulheres, velhos e crianças seguem igual trajeto, mas estão em condições desiguais para sobreviverem a todos aos percalços desse mesmo caminho.

Assim, temos dois olhares dirigidos a realidades distintas, mas que convergem para um ponto comum - a margem da História, contemplando aqueles que se encontram presos a um vórtice de desgraças trazidas direta ou indiretamente pela guerra. Há na mediação dessa realidade a projeção de uma imagem mais complexa do que um movimento prosaico de natureza bélica. Os discursos destes romances são capazes de criar um olhar que trespassa essa espiral de guerra em ambos os sentidos - de dentro para fora e vice versa, questionando e afirmando identidades nesse movimento em direção à periferia, e que é possível através dessa força centrífuga da guerra.

O romance $A$ costa dos murmúrios é apresentado em nove capítulos precedidos de uma primeira parte intitulada "Os gafanhotos", em que é narrada a celebração do casamento de Evita e Luís Alex, o aparecimento de incontáveis corpos de negros mortos pela ingestão de álcool etílico e a morte do alferes recém casado. A partir desse pequeno relato é que se inicia o questionamento do passado de vinte anos atrás com a intervenção de um narrador na terceira pessoa, o jornalista Sabino, autor do relato. Este narrador indicará a existência de um segundo narrador de quem será 
interlocutor, um “eu” narrador que é Eva Lopo. Essa instância narratária testemunhal interroga-se no presente para desconstruir o passado, selecionando os fatos que devem ser efetivamente narrados, e aqueles que devem ser omitidos. A narrativa não possui uma ordenação linear e segue um ritmo próprio, de característica subjetiva ordenada pelo fluxo da memória, ao contrário do que ocorre em "Os gafanhotos", que possui uma ordem temporal linear.

Portanto, de um lado temos esse "eu" narrador que também é personagem, e tem o comando de toda a segunda parte do romance. De outro lado, há o narrador em terceira pessoa da primeira parte - "Os gafanhotos" -, que não tem voz, apenas constrói o relato dos acontecimentos pertencentes ao passado, a partir das informações trazidas pela personagem Eva Lopo. Esse narrador em terceira pessoa que conduz plenamente a narrativa de "Os gafanhotos", entretanto, repassa definitivamente essa voz à Eva Lopo na segunda parte do romance, a quem caberá decidir pela interpretação das cenas ininteligíveis e incertas da memória. O narrador que está presente no relato deixa ao leitor essa visão através dos olhos da personagem central, ecoando apenas como interlocutor na segunda parte do romance. Essa construção narrativa reproduz um jogo de intratextualidade e oralidade através do qual se pretende construir solidamente uma história, a partir de lembranças e contradições vertidas nos relatos orais da personagem Eva Lopo.

O romance Ventos do apocalipse é apresentado em prólogo e vinte e cinco capítulos distribuídos em duas partes, que são precedidas por epígrafes: "Prólogo", em que temos a epígrafe Vinde todos e ouvi / Vinde todos com as vossas mulheres / e ouvi a chamada / Não quereis a nova música de timbila / que me vem do coração?, atribuída a Gomucomu (1943); "I Parte", que é precedida de um provérbio tsonga, Maxwela ku hanya! U ta sala u psi vona (Nasceste tarde! Verás o que eu não vi); e, "II Parte", cuja epígrafe é uma canção popular changane, A siku ni siko li ni psa lona (Cada dia tem a sua história). Estas epígrafes dão o tom do que será cada parte do romance, apresentando-se como motivo à narrativa que conta a história do êxodo dos sobreviventes de uma aldeia em busca de um local seguro. Num cenário apocalíptico conhecemos os pesadelos e os tormentos de uma gente sem esperança para quem "se o homem é a imagem de Deus, então Deus é um refugiado de guerra, magro, e com ventre farto de fome" (CHIZIANE, 1999, p. 184).

Interessante notar a construção deste romance que privilegia aspectos da oralidade como, por exemplo, o seu início em que há três pequenos contos que compõem o Prólogo, e servem de introdução à narrativa ("O marido cruel”, "Mata, que amanhã faremos outro" e "A ambição de 
Massupai”). Como na tradição bantu, Paulina Chiziane antes de começar a contar a sua história, ${ }^{9}$ traz ao leitor referência a pequenos contos e provérbios. A partir dessa introdução de elementos de formas simples e ancestrais, a contadora de histórias estabelece uma relação entre passado e presente, entre a tradição e a modernidade, indicando uma circularidade da vida e das histórias: “A terra gira e gira, a vida é uma roda, chegou a hora, a história repete-se, KARINGANA WA KARINGANA"(CHIZIANE, 1999, p. 22).

\section{$O$ feminino encanto}

A par da desconstrução da figura do herói que se dá em ambas narrativas, as figuras femininas participam de modo nuclear nas respectivas tramas. Em comum existem as mulheres consideradas coletivamente e aquelas anônimas que se denominam por seu pertencimento a um marido ou por uma particular condição. Uma espécie de distorção imagética em que as mulheres - como figuras em borrão, são deslocadas de suas próprias referências identitárias. No entanto, ao longo das narrativas ocorre a reconfiguração dessas identidades que coexistem e dialogam ativamente com as situações sociais que lhes servem de referência. Nesse percurso de revelação e afirmação identitárias estão, por exemplo, as personagens Eva Lopo e Helena de Tróia, em $A$ costa dos murmúrios, e Minosse, Wusheni, Mara e Emelina, em Ventos do apocalipse.

Como exemplo dessa denominação despersonalizada das mulheres encontramos no romance português algumas expressões como "as mulheres do Stella", "as raparigas de cabelo passado a ferro", ou ainda, "uma mulher de alferes", "a mulher do major", entre outras. Em contrapartida, no romance moçambicano vemos que a denominação que despersonaliza é ainda acompanhada de uma carga negativa como se percebe na expressão "mulheres rebeldes" ou ainda, "a mulher é a causa de todos os males do mundo; é do seu ventre que nascem os feiticeiros, as prostitutas" (CHIZIANE, 1999, p. 92).

\footnotetext{
${ }^{9}$ Francisco Noa corrobora em sua leitura da obra de Paulina Chiziane o privilégio de representações da oralidade e da tradição: "Mergulhar no oculto, no sobrenatural e na oralidade parece ser a estratégia literária encontrada por Paulina Chiziane para repensar as tendências e as orientações da sociedade moçambicana nos últimos tempos". In: NOA, Francisco. "Dez anos, dez autores, dez obras. Tendências temáticas e estéticas da literatura moçambicana". In: MARGATO, Izabel e GOMES, Renato Cordeiro (orgs.). Literatura / Política / Cultura. Belo Horizonte: Editora da UFMG, 2005, p. 159-160.
} 
É de observarem-se características psicossociais na própria nomeação das personagens centrais dos romances - Eva Lopo e Minosse, pois convergem para as mesmas, sistemas de atributações que se explicitam no nome a elas atribuído pela enunciação. Eva Lopo, a mulher portuguesa que acompanha o alferes para se casar no ultramar, carrega em seu nome duas referências fortes. A primeira delas é a referência bíblica da primeira mulher - Eva, que deve a sua existência à costela do primeiro homem, Adão. $\mathrm{O}$ nome do gênero feminino por excelência em sua origem e tradição judaico-cristã e ocidental, mas também na sua condição inferior, frágil e de dependência, e porque não dizer, também na sua condição de culpa e desgraça eterna pelo pecado original e conseqüente expulsão do Paraíso. Contudo, acompanha um apelido de família significativo à História do Expansionismo de Portugal: Lopo. Uma referência a figuras masculinas de posição relevante no reinado de D. Manuel I, por ocasião dos descobrimentos e grandes viagens marítimas: Lopo Soares de Albergaria, governador das Índias a partir de 1515, e Lopo Homem, ilustre cartógrafo e cosmógrafo português. É interessante notar a transformação em maturidade e consciência sugerida pela alteração da nomeação da personagem central em $A$ costa dos murmúrios. Jovem, crédula e alheia às razões e desrazões do Império Português, a personagem é tratada pelo diminutivo de seu nome - Evita, no relato que inicia o romance, intitulado "Os gafanhotos". Como todas as outras mulheres, é também mulher de alguém, no caso, do alferes Luís Alex. No entanto, ao fim do referido relato passa a ser tratada por "Eva Lopo", diminuindo a despersonalização presente na primeira parte do romance. Essa é uma das características marcantes da crescente afirmação identitária feminina que podemos encontrar ao longo do romance.

No caso da protagonista de Ventos do apocalipse, Minosse, ainda que Paulina Chiziane atribua a inspiração desta personagem a uma das vítimas da Guerra Civil na aldeia de Mananga ao norte de Moçambique, ocasião em que obteve grande parte do material que lhe serviu de referência para a escrita do romance, é inegável a coincidência com bases históricas de outra tradição na nomeação dessa personagem. Minosse é também a designação na língua italiana de Minos - rei de Creta, que encomendou a Dédalus a construção de um labirinto para encerrar o filho de sua esposa Pasífae, o Minotauro. Fato este que nos remete ao adágio contido no prólogo do romance moçambicano, designado como "ditado dos tempos do velho Império de Gaza", que diz: "mata, que amanhã faremos outro", referindo-se à imposição que se coloca à mulher para matar os próprios filhos pequenos que choram e denunciam ao inimigo a localização dos 
fugitivos. Consoante a mitologia, Minos desceu ao mundo subterrâneo depois de sua morte, e tornou-se um dos juízes dos mortos. Na obra épica de Dante, Minos é quem ouve as confissões dos mortos, atribuindo a pena de desígnio do círculo infernal que corresponda à gravidade da falta relatada. Assim, curiosamente, temos uma referência da tradição ocidental que se entrecruza ao percurso de Minosse, não apenas em seu nome, como também em sua relação com a morte, elemento transformador e libertador como vemos no trecho a seguir:

$\mathrm{Na}$ viagem fantasma, a velha Minosse vai à frente e nem os homens fortes conseguem seguir o passo dela. Caminha leve como uma pena. Todos se espantam. Os desgostos fizeram dela uma pessoa morta. Ela é um fantasma. Os fantasmas não têm corpo e nem sentem peso. Ela caminha leve e livre mesmo sem saber para onde vai (CHIZIANE, 1999, p. 155).

Minosse, a última esposa do régulo ${ }^{10}$ Sianga, sobrevive a inúmeras desgraças e vê morrerem seus filhos, seus netos e o seu senhor. Sem nenhum laço que a prenda ao mundo dos vivos, Minosse contempla livremente os sobreviventes de sua aldeia, que na fuga empreendida conhecem condições que os fazem desacreditar em sua própria identidade como ser humano. A caminhada que durará vinte e um dias, torna-se uma descida ao inferno da existência humana, e tudo se quebra: a fidelidade aos defuntos, as leis da tribo, o orgulho do homem, todas as normas mais elementares da vida humana. Isolada em uma realidade mágica que lhe aparta dos terríveis sofrimentos, Minosse retornará a sua plena consciência e ao convívio com os demais sobreviventes apenas quando encontrar um menino órfão a quem, com desvelo cuidará e embalará contando "historiazinhas fantásticas".

Estas duas figuras femininas centrais dos romances $A$ costa dos murmúrios e Ventos do apocalipse, que são Eva Lopo e Minosse, representam a busca pela reconstrução do "eu" esmagado pela guerra, na tentativa de emergir e transpor uma realidade de dupla opressão que é a condição da mulher inserida no contexto do conflito armado. O feminino encanto como presença indispensável no cenário da guerra, demonstra como a mulher se apresenta como elemento estabilizador e revelador das realidades representadas pelos romances.

\footnotetext{
${ }^{10}$ Chefe da aldeia.
} 


\section{Referências Bibliográficas}

CHIZIANE, Paulina. Ventos do apocalipse. Lisboa: Caminho, 1999.

GOMES, Kathleen. Nunca houve arma mais fulminante que a mulher. Entrevista com Paulina Chiziane. In Público, Leituras, Lisboa: p. 4-5, 13 nov 1999.

JAMISSE, Frederico. A riqueza do escritor vem da diversidade cultural. Paulina Chiziane, vida e obra. In Espaço África, Lisboa: p. 138, dez 2003 / jan 2004.

NOA, Francisco. Dez anos, dez autores, dez obras. Tendências temáticas e estéticas da literatura moçambicana. In MARGATO, Izabel e GOMES, Renato Cordeiro (orgs.). Literatura / Política / Cultura. Belo Horizonte: Editora da UFMG, 2005, p. 159-160.

VENTURA, Susana Ramos. Três romances em diálogo. São Paulo: FFLCH-USP, 2006 (tese de doutorado; texto policopiado). 